\title{
Fabrication and Characterization of Porous Silica Monolith by Sintering Silica Nanoparticles
}

\author{
Hiroshi Ikeda ${ }^{1}$, Shigeru Fujino ${ }^{2}$ \\ ${ }^{1}$ Division of Biomaterials, Department of Oral Functions, Kyushu Dental University, Fukuoka, Japan \\ ${ }^{2}$ Global Innovation Center, Kyushu University, Fukuoka, Japan \\ Email: fujino@gic.kyushu-u.ac.jp
}

How to cite this paper: Ikeda, H. and Fujino, S. (2017) Fabrication and Characterization of Porous Silica Monolith by Sintering Silica Nanoparticles. Journal of Minerals and Materials Characterization and Engineering, 5, 107-117.

https://doi.org/10.4236/jmmce.2017.53009

Received: April 25, 2017

Accepted: May 23, 2017

Published: May 26, 2017

Copyright ( 92017 by authors and Scientific Research Publishing Inc. This work is licensed under the Creative Commons Attribution International License (CC BY 4.0). http://creativecommons.org/licenses/by/4.0/

\begin{abstract}
This paper aims to fabricate over centimeter size of porous silica monolith having meso-pores with large surface area. A precursor of porous silica monolith was obtained by sintering a monolithic $\mathrm{SiO}_{2}$-poly (vinyl alcohol) (PVA) nanocomposite at $600^{\circ} \mathrm{C}-1100^{\circ} \mathrm{C}$. The sintering behavior was examined by means of Raman spectroscopy and a porosimetry. The PVA of the $\mathrm{SiO}_{2}-\mathrm{PVA}$ nanocomposite was combusted below $600^{\circ} \mathrm{C}$, subsequently the silica nanoparticles of the nanocomposite were sintered above $900^{\circ} \mathrm{C}$. The Raman spectroscopy suggested that amorphous structure of the porous silica monolith obtained above $1000^{\circ} \mathrm{C}$ was similar to that of a silica glass. The BET surface area and pore radius of the porous silica monolith decreased with increasing sintering temperature. These values were tailored in the range of ca. 0 - 291 $\mathrm{m}^{2} \cdot \mathrm{g}^{-1}$ and $5-25 \mathrm{~nm}$, respectively, by controlling the sintering temperature and time. The fabricated porous-silica monolith was translucent or opaque porous-silica depending on the pore size.
\end{abstract}

\section{Keywords}

Porous Silica, Monolith, Silica Nanoparticles, Silica Glass, PVA, Sintering

\section{Introduction}

A porous silica monolith of over centimeter size with a large surface area has been growing research interest for application to various industrial fields such as a catalysis, thermal insulation, adsorption, and separation. Sol-gel processes have been widely adapted for fabricating a porous silica monolith to control a pore size [1]-[8]. On the other hand, a particulate sol-gel process, which uses silica nanoparticles as a starting material, is also attractive alternative to fabricate a 
large porous silica monolith. For the past decades, the particulate sol-gel process has been developed for fabricating a porous silica precursor for a monolithic silica glass [2]. In the particulate sol-gel process, the porous silica precursor of porous silica monolith was prepared via gelation of a silica suspension and gel drying. It has been reported to fabricate over centimeter size of the porous silica precursor, as well as a silica glass monolith by sintering, with a shape of rods [9] [10] [11] [12] [13], tubes [14] [15] [16] [17] [18], rings [19], and plates [20]. However, some cracks often arise on a porous silica monolith during the gel drying step because a capillary force generates in the pores. This critical issue makes it difficult to fabricate large size and complex shape of porous silica monolith. In order to overcome the crack generation, important developments for the particulate sol-gel process have been widely studied. For instance, to suppress the crack generation during gel drying, many research groups have used dozens nanometer size of silica particles with adding some chemical additive [9]-[20].

Alternatively, we newly developed a particulate sol-gel process using single nanometer size of fumed silica particles, instead of several dozen nanometer sizes, in addition to use of poly(vinyl) alcohol (PVA) to avoid the crack generations during gel drying [21]. This process allows fabricating a porous $\mathrm{SiO}_{2}-\mathrm{PVA}$ nanocomposite monolith which can be used as a silica glass precursor. The monolithic $\mathrm{SiO}_{2}$-PVA nanocomposite, without any crack generation during drying of a gel, has relatively large surface area which can be controlled in the range of 100 - $300 \mathrm{~m}^{2} \cdot \mathrm{g}^{-1}$ [22]. In this study, we further developed the process to fabricate a porous silica monolith via sintering process by using the monolithic $\mathrm{SiO}_{2}$-PVA nanocomposite as the precursor. The surface area and pore size of the obtained porous silica monolith were tailored by the sintering temperature and time.

\section{Experimental}

\subsection{Fabrication of Porous Silica Monolith}

An $\mathrm{SiO}_{2}$-PVA nanocomposite, which is the precursor of a porous silica monolith, was prepared by using fumed silica nanoparticles (Aerosil 300, BET surface area of $300 \mathrm{~m}^{2} \cdot \mathrm{g}^{-1}$ according to the supplier, Nippon Aerosil, Japan) and PVA (polymerization degree of 1500 - 1800, Wako pure chemical Industries, Japan) as starting materials by a following procedure [21]. Fumed silica was added distilled water adjusted at $\mathrm{pH} 3$ followed by dispersing by means of an ultra-sonication for $1 \mathrm{~h}$ to obtain $8 \mathrm{wt} \%$ of a silica suspension. Meanwhile, PVA was dissolved into distilled water and stirred using a magnetic stirrer at a speed of $800 \mathrm{rpm}$ to prepare $8 \mathrm{wt} \%$ of a PVA solution. Then, the obtained silica suspension and PVA solution were mixed for $12 \mathrm{~h}$ to obtain $80 \mathrm{SiO}_{2}$-20PVA (wt\%) suspension. The resulting $\mathrm{SiO}_{2}$-PVA suspension was cast into a Teflon container and dried at $30^{\circ} \mathrm{C}$ under atmospheric pressure in an oven. A gelation of the suspension was taken place gradually and then a monolithic $\mathrm{SiO}_{2}$-PVA nanocomposite was formed.

A monolithic porous silica monolith was fabricated by calcining the $\mathrm{SiO}_{2}-\mathrm{PVA}$ nanocomposite at $600^{\circ} \mathrm{C}$ for $3 \mathrm{~h}$ in air to combustion of the PVA, followed by 
sintered at $600^{\circ} \mathrm{C}-1100^{\circ} \mathrm{C}$ for $5,10,20,30 \mathrm{~min}$, or $1 \mathrm{~h}$, respectively, in air.

\subsection{Characterization of Porous Silica Monolith}

BET surface area and pore size distribution of the porous silica monolith were determined by means of a porosimeter (BELSORP-mini, Bel Japan Inc., Japan) via Brunauer-Emmett-Teller (BET) method and Barrett-Joyner-Halenda (BJH) method. Structural change in the porous silica monolith by the sintering was examined by means of a Raman spectrometer (STR-HTUV, Seki Technotron Co.) equipped with a He-Cd laser. Optical transmittances of the porous silica monolith were measured by means of a spectrophotometer (U-3500, Hitachi High-Technologies Co., Japan).

\section{Results and Discussion}

\subsection{Sintering Behavior of Silica Nanoparticles}

Figure 1 shows pore size distribution of the $\mathrm{SiO}_{2}$-PVA nanocomposite. It is clearly seen that the $\mathrm{SiO}_{2}$-PVA nanocomposite had mesopores with radius below $20 \mathrm{~nm}$ and BET surface area of $141 \mathrm{~m}^{2} \cdot \mathrm{g}^{-1}$. This $\mathrm{SiO}_{2}-\mathrm{PVA}$ nanocomposite was used as a precursor for a porous silica monolith. The $\mathrm{SiO}_{2}-\mathrm{PVA}$ nanocomposite precursor was sintered at given temperature in the range of $600^{\circ} \mathrm{C}-1100^{\circ} \mathrm{C}$ to fabricate a porous silica monolith. Figure 2 denotes dependence of BET surface area on sintering temperature for the sintered samples. BET surface area for the sample sintered at $600^{\circ} \mathrm{C}$ was $291 \mathrm{~m}^{2} \cdot \mathrm{g}^{-1}$. This value is larger than that of the $\mathrm{SiO}_{2}$-PVA nanocomposite precursor and comparable to that of the as-received fumed silica particles. This result indicated that the PVA in the $\mathrm{SiO}_{2}-\mathrm{PVA}$ nanocomposite was just combusted at the temperature and sintering of the silica nanoparticles did not occur. As increasing sintering temperature up to $900^{\circ} \mathrm{C}$, BET surface area of the sample decreased with increasing treatment temperature. Over $900^{\circ} \mathrm{C}$, BET surface area of the sample abruptly decreased with increasing sintering temperature. This fact suggested that the sintering of silica

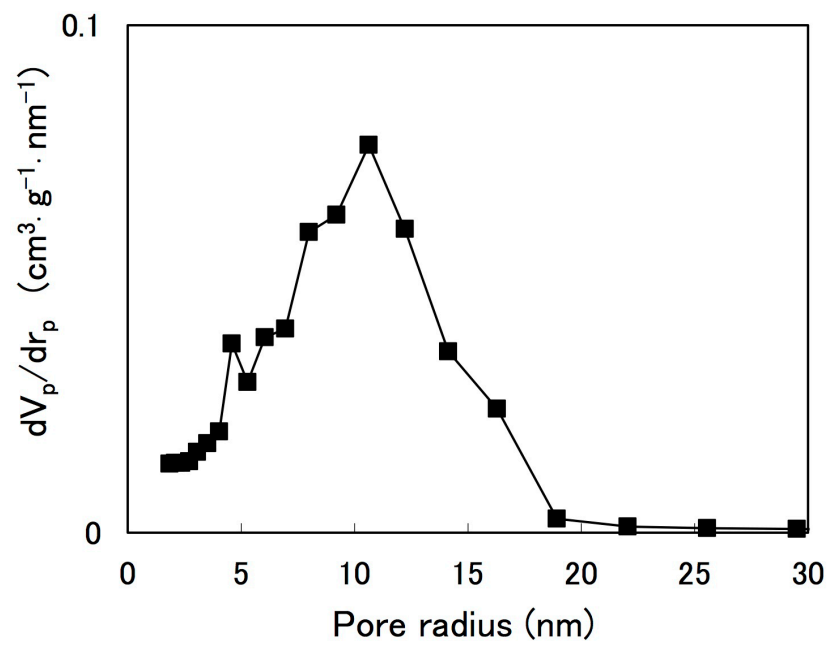

Figure 1. Pore size distribution of the $\mathrm{SiO}_{2}$-PVA nanocomposite obtained by the $\mathrm{BJH}$ method. 


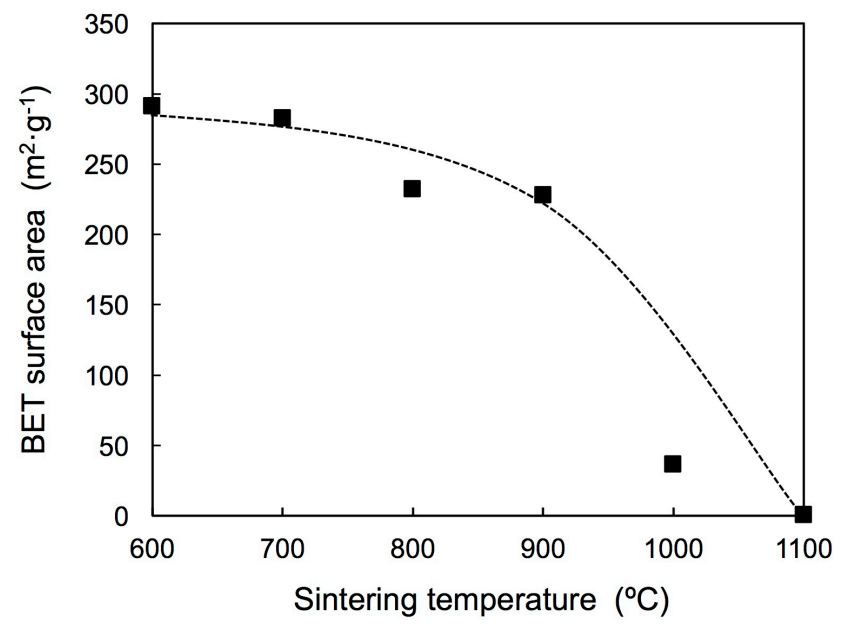

Figure 2. Dependence of sintering temperature on BET surface area for the porous silica monolith obtained by calcining the $\mathrm{SiO}_{2}$-PVA nanocomposite at $600^{\circ} \mathrm{C}$ for $3 \mathrm{~h}$ in air, followed by sintering at each temperature for $1 \mathrm{~h}$ in air.

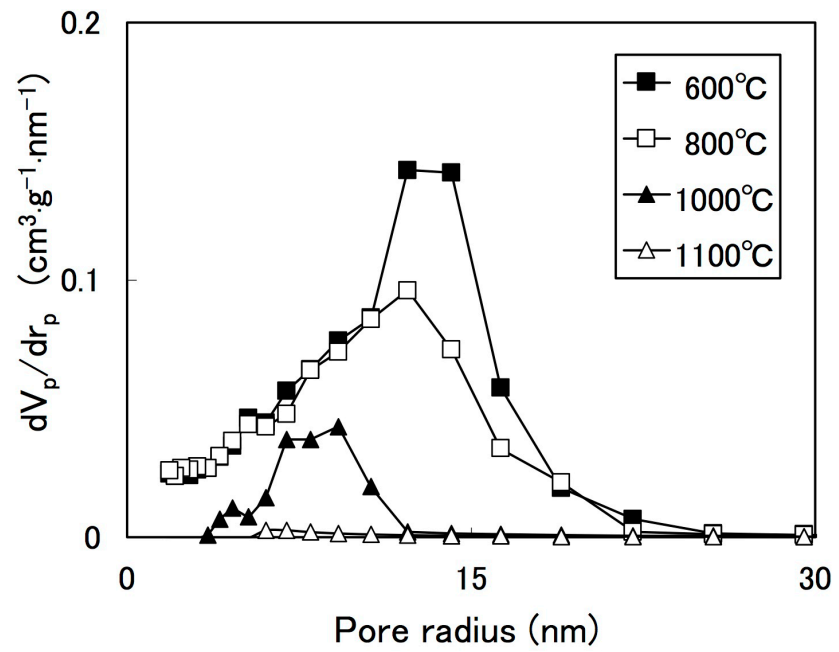

Figure 3. Pore size distributions of porous silica monolith obtained by calcining the $\mathrm{SiO}_{2}$ PVA nanocomposite at $600^{\circ} \mathrm{C}$ for $3 \mathrm{~h}$ in air, followed by sintering at each temperature for $1 \mathrm{~h}$ in air.

nanoparticles would occur above $900^{\circ} \mathrm{C}$. At $1100^{\circ} \mathrm{C}$, BET surface area reached to zero. This result indicates that sintering of the silica nanoparticles was accomplished at $1100^{\circ} \mathrm{C}$ and dense (non-porous) body was formed. Figure 3 shows dependence of the sintering temperature on pore size distributions of the sintered silica samples. It is clearly seen that the sintered silica samples had broad peaks with the pore radius below $25 \mathrm{~nm}$. For the sample sintered at $600^{\circ} \mathrm{C}$, the peak center of pore size distribution is located at $\sim 15 \mathrm{~nm}$. As increasing sintering temperature, the peak was shifted to smaller side and its peak intensity became small. For the sample obtained at $1100^{\circ} \mathrm{C}$, no pores exist in the examined range.

Sintering behavior of the silica nanoparticles of the $\mathrm{SiO}_{2}-\mathrm{PVA}$ nanocomposite was elucidated in terms of change in amorphous structure by using the Raman spectroscopy. Figure 4 depicts Raman spectra of the sintered silica samples. Raman spectrum for a commercial silica glass was also given in the figure to 


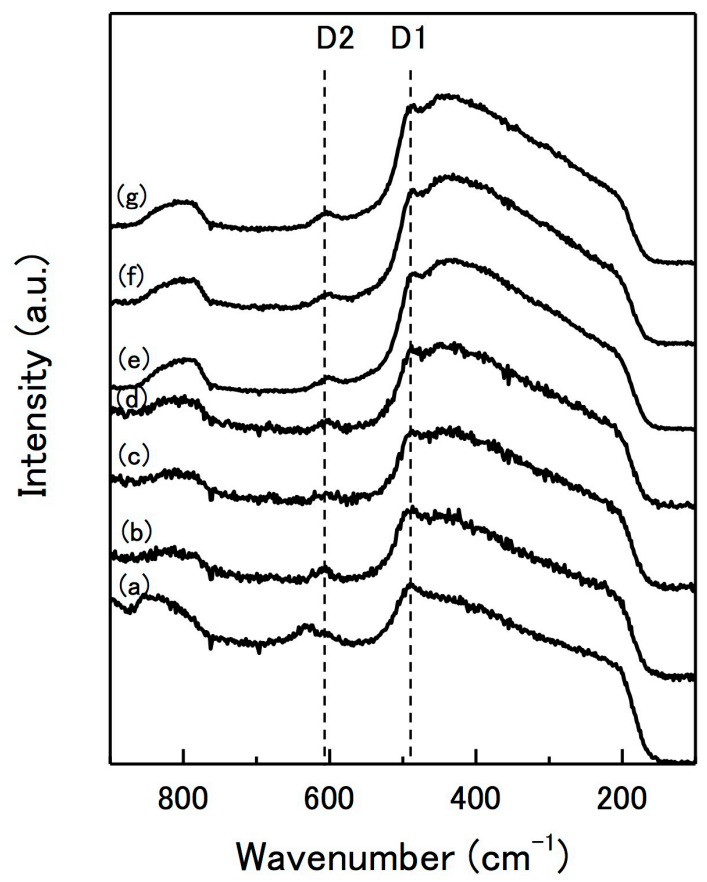

Figure 4. Raman spectra of (a) $\mathrm{SiO}_{2}$-PVA nanocomposite, and the sintered samples at (b) $600^{\circ} \mathrm{C}$, (c) $800^{\circ} \mathrm{C}$, (d) $900^{\circ} \mathrm{C}$, (e) $1000^{\circ} \mathrm{C}$, (f) $1100^{\circ} \mathrm{C}$ for $1 \mathrm{~h}$ in air, and (g) a commercial silica glass.

compare the spectra for the sintered samples. For the spectrum of the commercial silica glass, some characteristic peaks attributed to an amorphous silica were observed: The bands at around 500 and $620 \mathrm{~cm}^{-1}$ are assigned respectively to symmetric oxygen breathing vibrations of regular four-membered (D1) and three-membered (D2) silica rings [23] [24] [25]. The broad band at around 430 $\mathrm{cm}^{-1}$ is attributed to bending motions of oxygen atoms in the random network of silica glass [26]. In the present study, we focused the bands for D1 and D2 to elucidate the sintering behavior of silica nanoparticles because D1 and D2 bands are sensitive to change in the amorphous structure. Figure 5 depicts relative intensities for $\mathrm{D} 1$ and $\mathrm{D} 2$ bonds of each sample. For the spectrum of $\mathrm{SiO}_{2}-\mathrm{PVA}$ nanocomposite, the intensities for D1 and D2 bands relatively larger than those of the commercial silica glass. As increasing sintering temperature, intensities for D1 and D2 bands decreased. As a result, the intensities for the sample sintered at $1100^{\circ} \mathrm{C}$ became to be comparable to those of the commercial silica glass. These changes in the intensities would involve structural change in silica membered rings. Amorphous silica contains silica membered rings such as four-membered (D1) and three-membered (D2) silica rings, and larger membered silica rings. In an industry, the fumed silica nanoparticle, used in this study as the starting material, is produced by hydrothermal reaction of $\mathrm{SiCl}_{4}$ in oxyhydrogen flame at high temperature. The production process for the fumed silica nanoparticles gives characteristic surface properties such as large surface area and structural defects such as four-membered (D1) and three-membered (D2) silica rings. These four-membered and three-membered silica rings are considered to be less stable than the other membered rings such as six-membered rings [27]. Thus, 


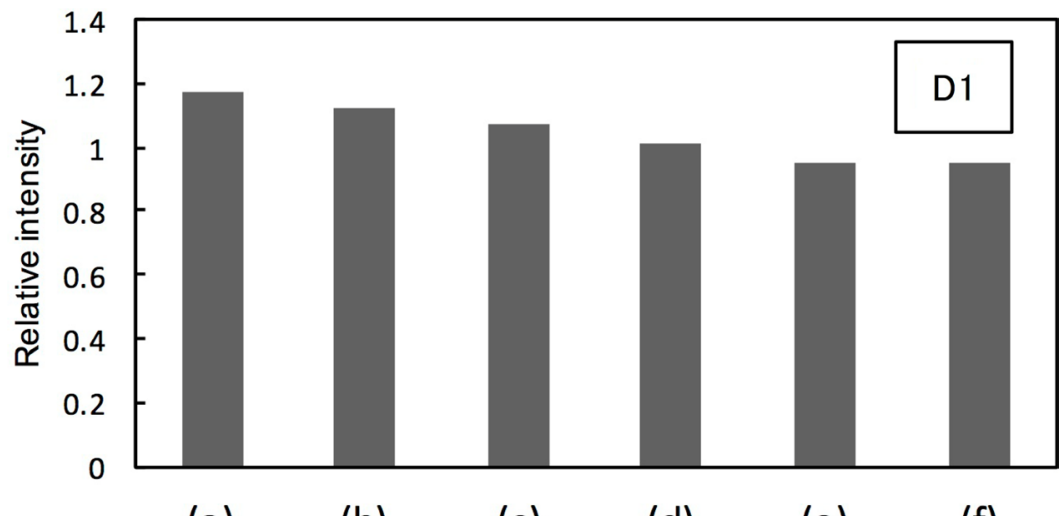

$\begin{array}{llllll}\text { (a) } & \text { (b) } & \text { (c) } & \text { (d) } & \text { (e) } & \text { (f) }\end{array}$

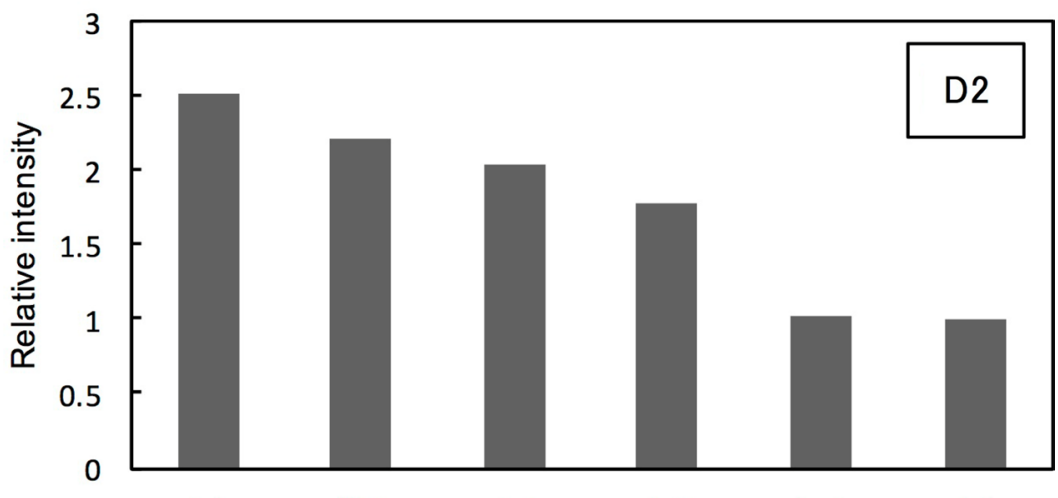

$\begin{array}{llllll}\text { (a) } & \text { (b) } & \text { (c) } & \text { (d) } & \text { (e) } & \text { (f) }\end{array}$

Figure 5. Relative intensities of D1 and D2 bands for the Raman spectra of the samples as given in Figure 4. The intensities were normalized by dividing D1 and D2 bands intensities respectively by those of a commercial silica glass. (a) $\mathrm{SiO}_{2}$-PVA nanocomposite, and the sintered sample at (b) $600^{\circ} \mathrm{C}$, (c) $800^{\circ} \mathrm{C}$, (d) $900^{\circ} \mathrm{C}$, (e) $1000^{\circ} \mathrm{C}$, (f) $1100^{\circ} \mathrm{C}$ for $1 \mathrm{~h}$ in air.

such small membered rings would be transformed to the other stable structure during sintering. Figure 4 and Figure 5 suggested that the structural change of the amorphous silica was observed in the sample sintered above $900^{\circ} \mathrm{C}$. Consequently, the amorphous structure for the sample sintered at $1100^{\circ} \mathrm{C}$ is comparable to that of the commercial silica glass. From these results, it is considered that sintering of silica nanoparticles occurs above $900^{\circ} \mathrm{C}$, associated with change in the amorphous structure between transformed from three- and four-membered silica rings to the other membered rings.

\subsection{Characterization of Porous Silica Monolith Obtained by Sintering}

Porous structure of sintered silica monolith is also controlled by sintering time, as well as sintering temperature. Figure 6 shows variation of BET surface areas by change in the treatment time at $1100^{\circ} \mathrm{C}$ in air. The BET surface area of the sample decreased with increasing time. As shown in Figure 7, the pore size distribution for the sample shifted to lower side with increasing sintering time. These results indicated that the porous structure was tailored with BET surface 


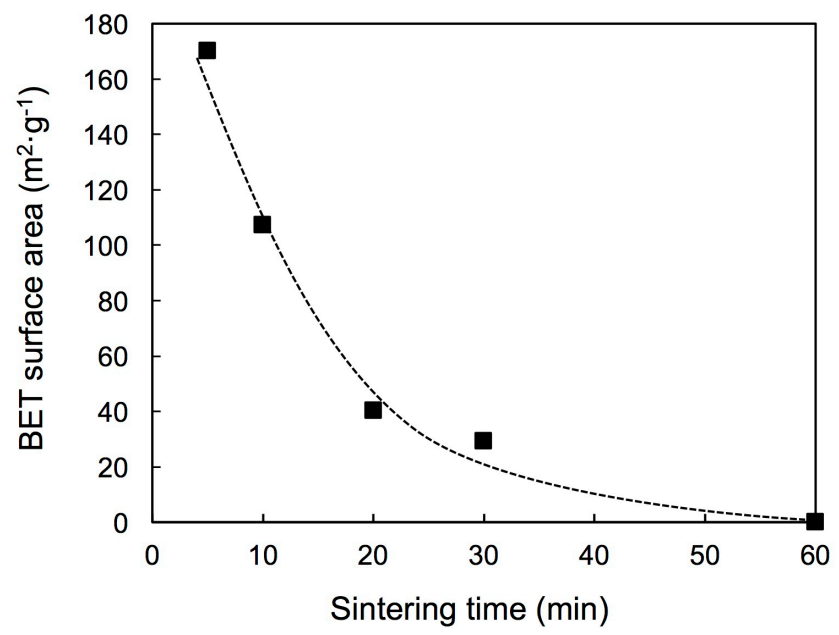

Figure 6. BET surface areas of porous silica monolith obtained by calcining the $\mathrm{SiO}_{2}$ PVA nanocomposite at $600^{\circ} \mathrm{C}$ for $3 \mathrm{~h}$ in air, followed by sintering at $1100^{\circ} \mathrm{C}$ for given time in air.

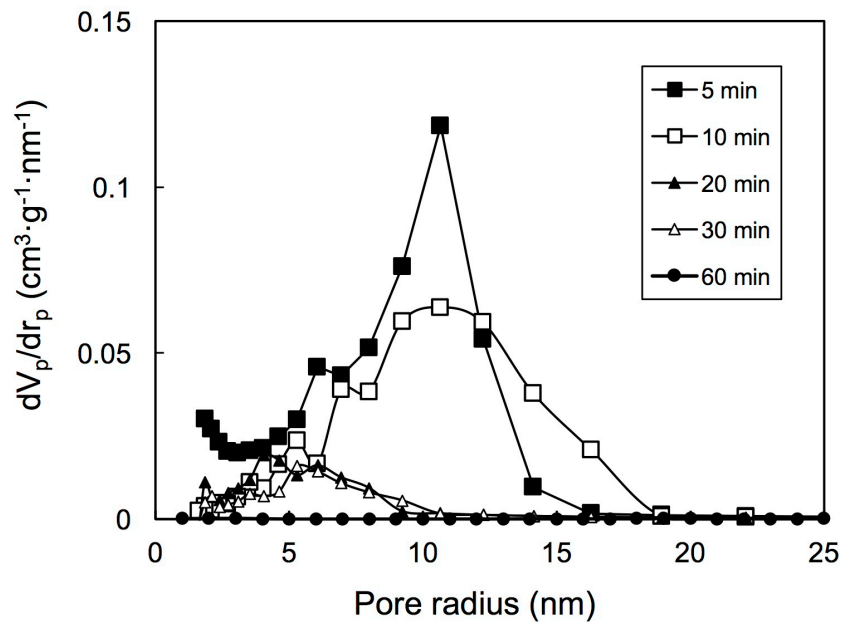

Figure 7. Pore size distributions of the porous silica monolith obtained by calcining the $\mathrm{SiO}_{2}$-PVA nanocomposite at $600^{\circ} \mathrm{C}$ for $3 \mathrm{~h}$ in air, followed by sintering at $1100^{\circ} \mathrm{C}$ for given temperature in air.

area in the range of ca. $0-300 \mathrm{~m}^{2} \mathrm{~g}^{-1}$ and pore size distribution in ca. $5-30 \mathrm{~nm}$, respectively.

The sintering time affects not only on the porous structure but also an optical transmittance in UV-Vis and near-infrared regions. Figure 8 shows optical transmittance in UV-Vis and near-infrared regions for the sintered samples. For the sample (a) obtained by sintering at $1100^{\circ} \mathrm{C}$ for $5 \mathrm{~min}$, whose BET surface area was $146 \mathrm{~m}^{2} \cdot \mathrm{g}^{-1}$, the spectrum indicated opaque in the examined range. In contrast, for the sample; (b) obtained by sintering at $1100^{\circ} \mathrm{C}$ for $30 \mathrm{~min}$, whose BET surface area was $20 \mathrm{~m}^{2} \cdot \mathrm{g}^{-1}$, the sample was translucent. In order to clarify the relation between the morphology and the optical transmittance, we observed the microstructure of the sintered sample by using FE-SEM. Figure 9 shows FE-SEM images for these samples. For the opaque sample, the silica grains with several hundred nanometer and inter-particle pores were clearly observed. For 


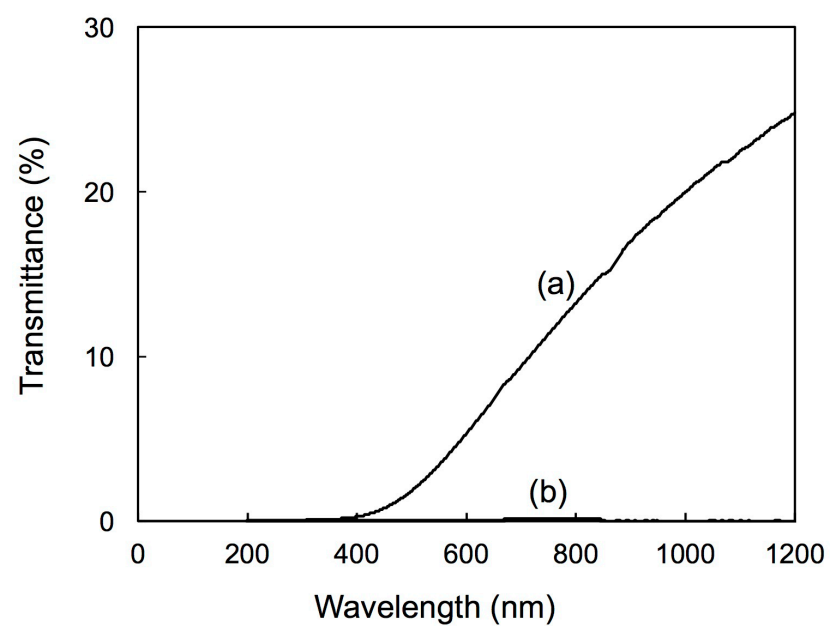

Figure 8. Optocal transmission spectra of the porous silica monolith obtained by sintering at $1100^{\circ} \mathrm{C}$ for (a) $5 \mathrm{~min}$, (b) $30 \mathrm{~min}$.
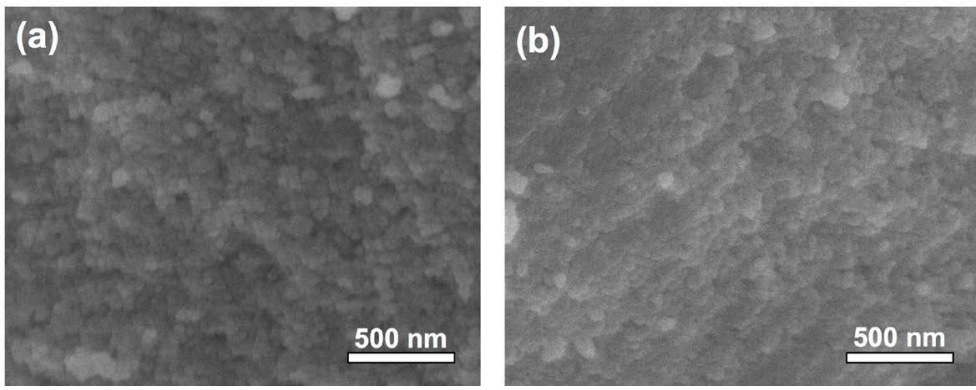

Figure 9. FE-SEM images of the silica monolith obtained by sintering at $1100^{\circ} \mathrm{C}$ for (a) 5 min, (b) $30 \mathrm{~min}$.

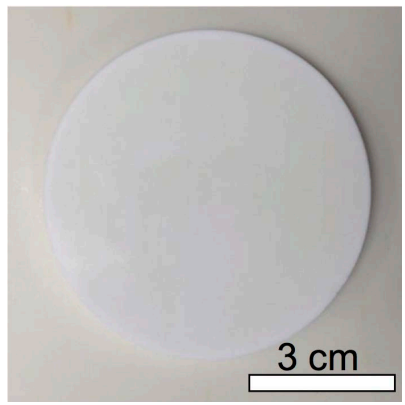

Figure 10. Photograph of the porous silica monolith obtained by sintering at $1100^{\circ} \mathrm{C}$ for 5 min.

the translucent sample, meanwhile, the grain size became large and inter-particle pore size was reduced. It is considered that decreasing of inter-particle pore size reduced a light scattering at the particle interface. Therefore, transmittance of the porous silica increases with decreasing BET surface areas.

Figure 10 shows the porous silica monolith fabricated by using the present method. We obtained the disc shape with $63 \mathrm{~mm}$ diameter and $7 \mathrm{~mm}$ thickness. No crack was observed by the naked eye. The BET surface area for the porous silica monolith (e.g. $146 \mathrm{~m}^{2} \cdot \mathrm{g}^{-1}$ ) is much larger than that of silica monolith obtained by a conventional colloidal gel process (e.g. less than $50 \mathrm{~m}^{2} \cdot \mathrm{g}^{-1}$ ) [2] 
Therefore, the present method is attractive alternative to fabricate porous silica monolith with over centimeter size possessing mesopores.

\section{Conclusion}

A porous silica monolith was fabricated by sintering the monolithic $\mathrm{SiO}_{2}$-PVA nanocomposite containing silica nanoparticles. Sintering of the silica nanoparticles occurred above $900^{\circ} \mathrm{C}$ with change in the amorphous silica structure. The BET surface area and pore radius can be tailored in the range of $0-300 \mathrm{~m}^{2} \cdot \mathrm{g}^{-1}$ and $5-25 \mathrm{~nm}$, respectively, by optimization of sintering temperature and time. We obtained successfully large size of the porous monolith of the disc shape with large surface area. In future, it is expected that complex shape (e.g. tube, honeycomb structure) products are fabricated by the present method.

\section{Acknowledgements}

This work was supported by JSPS KAKENHI Grant No. 26420756. S. Fujino wishes to thank the Japan Mining Promotive Foundation and the Mining and Materials Processing Institute of Japan for financial support.

\section{References}

[1] Nakanishi, K. and Soga, N. (1992) Phase-Separation in Silica Sol-Gel System Containing Polyacrylic-Acid. 2. Effects of Molecular-Weight and Temperature. Journal of Non-Crystalline Solids, 139, 14-24. https://doi.org/10.1016/S0022-3093(05)80801-4

[2] Kirkbir, F., Murata, H., Meyers, D., Chaudhuri, S.R. and Sarkar, A. (1996) Drying and Sintering of Sol-Gel Derived Large $\mathrm{SiO}_{2}$ Monoliths. Journal of Sol-Gel Science and Technology, 6, 203-217. https://doi.org/10.1007/BF00402691

[3] Kajihara, K., Hirano, M. and Hosono, H. (2009) Sol-Gel Synthesis of Monolithic Silica Gels and Glasses from Phase-Separating Tetraethoxysilane-Water Binary System. Chemical Communications, 47, 2580-2582. https://doi.org/10.1039/b900887j

[4] Kanamori, K. and Nakanishi, K. (2011) Controlled Pore Formation in Organotrialkoxysilane-Derived Hybrids: from Aerogels to Hierarchically Porous Monoliths. Chemical Society Reviews, 40, 754-770. https://doi.org/10.1039/C0CS00068J

[5] Inayat, A., Reinhardt, B., Uhlig, H., Einicke, W.-D. and Enke, D. (2013) Silica Monoliths with Hierarchical Porosity Obtained from Porous Glasses. Chemical Society Reviews, 42, 3753-3764. https://doi.org/10.1039/C2CS35304K

[6] Galarneau, A., Abid, Z., Said, B., Didi, Y., Szymanska, K., Jarzębski, A., Tancret, F., Hamaizi, H., Bengueddach, A. and Di Renzo, F. (2016) Synthesis and Textural Characterization of Mesoporous and Meso-/Macroporous Silica Monoliths Obtained by Spinodal Decomposition. Inorganics, 4, 9. https://doi.org/10.3390/inorganics4020009

[7] Baetens, R., Jelle, B.P. and Gustavsen, A. (2011) Aerogel Insulation for Building Applications: A State-of-the-Art Review. Energy and Buildings, 43, 761-769. https://doi.org/10.1016/j.enbuild.2010.12.012

[8] Kajihara, K. (2013) Recent Advances in Sol-Gel Synthesis of Monolithic Silica and Silica-Based Glasses. Journal of Asian Ceramic Societies, 1, 121-133. https://doi.org/10.1016/j.jascer.2013.04.002

[9] Rabinovich, E.M., Johnson, D.W., Macchesney, J.B. and Vogel, E.M. (1982) Prepa- 
ration of Transparent High-Silica Glass Articles from Colloidal Gels. Journal of Non-Crystalline Solids, 47, 435-439. https://doi.org/10.1016/0022-3093(82)90221-6

[10] Scherer, G.W. and Luong, J.C. (1984) Glasses from Colloids. Journal of Non-Crystalline Solids, 63, 163-172. https://doi.org/10.1016/0022-3093(84)90395-8

[11] Clasen, R. (1987) Preparation and Sintering of High-Density Green Bodies to HighPurity Silica Glasses. Journal of Non-Crystalline Solids, 89, 335-344. https://doi.org/10.1016/S0022-3093(87)80276-4

[12] Johnson, D.W., Rabinovich, E.M., Fleming, D.A. and Macchesney, J.B. (1989) Improvement in Colloidal Sol-Gel $\mathrm{SiO}_{2}$ Glass by Attrition of Aggregates in Sols. Journal of Materials Science, 24, 2214-2220. https://doi.org/10.1007/BF02385444

[13] Satha, H., Haddad, A. and Phalippou, J. (2003) Silica Glass from Aerosil by Sol-Gel Process: Densification and Textural Properties. International Journal of Thermophysics, 24, 885-893. https://doi.org/10.1023/A:1024013005413

[14] Rabinovich, E.M., Johnson, D.W., Macchesney, J.B. and Vogel, E.M. (1983) Preparation of High-Silica Glasses from Colloidal Gels. 1. Preparation for Sintering and Properties of Sintered Glasses. Journal of the American Ceramic Society, 66, 683688. https://doi.org/10.1111/j.1151-2916.1983.tb10529.x

[15] Johnson, D.W., Rabinovich, E.M., Macchesney, J.B. and Vogel, E.M. (1983) Preparation of High-Silica Glasses from Colloidal Gels. 2. Sintering. Journal of the American Ceramic Society, 66, 688-693.

https://doi.org/10.1111/j.1151-2916.1983.tb10530.x

[16] Wood, D.L., Rabinovich, E.M., Johnson, D.W., Macchesney, J.B. and Vogel, E.M. (1983) Preparation of High-Silica Glasses from Colloidal Gels. 3. Infrared Spectrophotometric Studies. Journal of the American Ceramic Society, 66, 693-699. https://doi.org/10.1111/j.1151-2916.1983.tb10531.x

[17] Srdic, V. and Radonjic, L. (1992) Gelation and Microstructure of Particulate Silica. Ceramics International, 18, 73-80. https://doi.org/10.1016/0272-8842(92)90034-B

[18] MacChesney, J.B., Johnson, D.W., Bhandarkar, S., Bohrer, M.P., Fleming, J.W., Monberg, E.M. and Trevor, D.J. (1998) Optical Fibers by a Hybrid Process Using Sol-Gel Silica Overcladding Tubes. Journal of Non-Crystalline Solids, 226, 232-238. https://doi.org/10.1016/S0022-3093(98)00407-4

[19] Rabinovich, E.M., Johnson, D.W., Mishkevich, A., Chandross, E.A. and Thomson, J. (2003) Sol-Gel Particulate Float Process to Make Vitreous Silica Bodies. Journal of Sol-Gel Science and Technology, 28, 19-29. https://doi.org/10.1023/A:1025624801014

[20] Toki, M., Miyashita, S., Takeuchi, T., Kanbe, S. and Kochi, A. (1988) A Large-Size Silica Glass Produced by a New Sol-Gel Process. Journal of Non-Crystalline Solids, 100, 479-482. https://doi.org/10.1016/0022-3093(88)90067-1

[21] Ikeda, H., Fujino, S. and Kajiwara, T. (2011) Preparation of $\mathrm{SiO}_{2}$-PVA Nanocomposite and Monolithic Transparent Silica Glass by Sintering. Journal of the Ceramic Society of Japan, 119, 65-69. https://doi.org/10.2109/jcersj2.119.65

[22] Ikeda, H. and Fujino, S. (2014) Composition and pH Dependence on Aggregation of $\mathrm{SiO}_{2}$-PVA Suspension for the Synthesis of Porous $\mathrm{SiO}_{2}$-PVA Nanocomposite. Journal of Porous Materials, 21, 1143-1149. https://doi.org/10.1007/s10934-014-9866-8

[23] Brinker, C.J., Tallant, D.R., Roth, E.P. and Ashley, C.S. (1986) Sol-Gel Transition in Simple Silicates. 3. Structural Studies during Densification. Journal of Non-Crystalline Solids, 82, 117-126. https://doi.org/10.1016/0022-3093(86)90119-5

[24] Uchino, T., Tokuda, Y. and Yoko, T. (1998) Vibrational Dynamics of Defect Modes 
in Vitreous Silica. Physical Review B, 58, 5322-5328.

https://doi.org/10.1103/PhysRevB.58.5322

[25] Pasquarello, A. and Car, R. (1998) Identification of Raman Defect Lines as Signatures of Ring Structures in Vitreous Silica. Physical Review Letters, 80, 5145-5147. https://doi.org/10.1103/PhysRevLett.80.5145

[26] Uchino, T., Aboshi, A., Kohara, S., Ohishi, Y., Sakashita, M. and Aoki, K. (2004) Microscopic Structure of Nanometer-Sized Silica Particles. Physical Review B, 69, Article ID: 155409. https://doi.org/10.1103/physrevb.69.155409

[27] Galeener, F. (1982) Planar Rings in Glasses. Solid State Communications, 44, 1037 1040. https://doi.org/10.1016/0038-1098(82)90329-5

Submit or recommend next manuscript to SCIRP and we will provide best service for you:

Accepting pre-submission inquiries through Email, Facebook, LinkedIn, Twitter, etc. A wide selection of journals (inclusive of 9 subjects, more than 200 journals)

Providing 24-hour high-quality service

User-friendly online submission system

Fair and swift peer-review system

Efficient typesetting and proofreading procedure

Display of the result of downloads and visits, as well as the number of cited articles Maximum dissemination of your research work

Submit your manuscript at: http://papersubmission.scirp.org/

Or contact jmmce@scirp.org 